\title{
Magnitude of Safe Delivery Services Utilization and Associated Factors Among Women of Childbearing Age in Egela Sub-Woreda, Tigray, Northern Ethiopia
}

\author{
Andemariyam Yohannes ${ }^{1}$, Teshome Gobana ${ }^{2}$, Fitsum Araya $^{3}$, Nigusse Obse ${ }^{4}$ \\ ${ }^{1}$ Department of Biomedical Sciences, College of Health Sciences, Samara University, Samara, Ethiopia \\ ${ }^{2}$ Department of Biomedical Sciences, College of Health Sciences, Jimma University, Jimma, Ethiopia \\ ${ }^{3}$ Department of Gynecology \& Obstetrics, College of Health Sciences, Jimma University, Jimma, Ethiopia \\ ${ }^{4}$ Department of Biomedical Sciences, Adama Hospital Medical College, Adama, Ethiopia
}

Email address:

anduyo2002@gmail.com (A. Yohannes),niguse11@gmail.com (N. Obse)

\section{To cite this article:}

Andemariyam Yohannes, Teshome Gobana, Fitsum Araya, Nigusse Obse. Magnitude of Safe Delivery Services Utilization and Associated Factors Among Women of Childbearing Age in Egela Sub-Woreda, Tigray, Northern Ethiopia. Journal of Gynecology and Obstetrics. Vol. 4, No. 6, 2016, pp. 44-52. doi: 10.11648/j.jgo.20160406.13

Received: September 22, 2016; Accepted: October 26, 2016; Published: December 8, 2016

\begin{abstract}
In Ethiopia, the levels of maternal and infant mortality and morbidity are among the highest in the world. Community based studies about safe delivery service utilization are not enough. As per the few studies done, professional assisted delivery is low in the country and particularly in Tigray region where the study was conducted. Community based cross sectional both quantitative and qualitative study were conducted in subworeda Egela, Northern Ethiopia on assessment of safe delivery service utilization and associated factors in mothers of childbearing age. The data for the quantitative method was collected using a pretested structured questionnaire on a sample of 380 mothers. The qualitative data were collected by FGDs with mothers of childbearing age, with the administrative bodies in the Subworeda and health professionals. The data were entered and analyzed using SPSS 16.0 and the appropriate statistical methods was used in the presentation, test of significant associations of variables at CI of $95 \%$. The study revealed that $10.3 \%$ of the women deliver in health institution. $25 \%$ of the urban and $6.3 \%$ of the rural women deliver at health institutions. The socio-demographic variables s, obstetric factors, ANC attendance, TT vaccination \& distance of health institution, were significantly associated with institutional delivery. In general this study revealed that the proportion of births delivered in the health institutions were unsatisfactory. The socio-demographic, obstetric and health service factors like distance of health institution were determinant factors. Therefore, establishing centers for emergency obstetric care other than the health center in accessible areas, providing health education for women of childbearing age by focusing on the Multi-para are the possible solutions should be recommended.
\end{abstract}

Keywords: Safe Delivery, Maternal and Infant Mortality and Morbidity, Professional Assisted Delivery, Women of ChildBearing Age

\section{Introduction}

Maternal death is death of a woman while pregnant or within 42 days of termination of pregnancy, irrespective of the duration of pregnancy, from any cause related to or aggravated by the pregnancy or its management but not from accidental causes [1]. Globally, more than half a million women die every year because of complications related to pregnancy and childbirth. Of that half a million, $95 \%$ are from developing nations [2], with about a half occurring in Sub Saharan Africa while about 187,000 occur in Asia [3].

In Ethiopia the levels of maternal and infant mortality and morbidity are among the highest in the world [4]. Maternal mortality ratio is estimated at $673 / 100,000$ live births $[1,5]$. In Tigray MMR 505-576 per 100,000 live births based on community survey in 2001 [6]. Tigray has shortage of skilled birth attendants and has low utilizations of obstetrics care. The rural women have poor access to basic emergency obstetric care and comprehensive emergency care [7]. 
Proportion of deliveries attended by skilled health care personnel, around 1990 and around 2006 in Sub-Saharan Africa was 42 and 47 percent respectively [8].

In developing countries the proportion of births attended by skilled birth attendants increased from $42 \%$ to $53 \%$ over the decade from 1990 to 2000. Studies had been done in Ethiopia by different investigators on roles of sociodemographic factors on utilization of maternal health care services [5] and utilization of maternal health care services in Ethiopia [9]. Those studies assess the magnitude and main factors that deter mother from using maternal health care services.

However, the fact that the factors; cultural, beliefs and attitudes, access to the health care giving institutions and other factors that interfere maternal delivery service utilization are different in different communities, conducting more community based study is very crucial to undertake necessary interventions by the concerned bodies accordingly. Therefore, this study will contribute by availing the current magnitude of utilization of safe delivery service and factors that affect it in the study area.

\section{Methods \& Materials}

\subsection{Study Area}

Community based cross-sectional study was conducted in
Subworeda Egela, which is located around $190 \mathrm{kms}$ far from the capital city of Tigray Regional State, Mekelle to the North West with total population of 46,462 .

\subsection{Sampling and Sample Size Determination}

\subsubsection{Quantitative Data}

The sample size was determined by considering delivery service utilization in the region to be $12.7 \%$ [10]. The actual size for the study is computed using one population proportion formula as indicated below.

Thus, the sample size was

$$
\mathrm{n}=\frac{(\mathrm{Z} \alpha / 2)^{2} \times \mathrm{P}(1-\mathrm{p})}{d^{2}}
$$

$\mathrm{n}=172$ plus $10 \%$ non - response rate $\&$ design effect of 2

Total $=380$ sampled women were included

Stratified multistage sampling method was used for quantitative data collection by dividing the Sub-Woreda in to Urban and Rural kebeles. Pre tested interviewer administered questionnaires was used to collect data from respondents.

\subsubsection{Qualitative Data}

A total of 4 focus group discussion (FGDs) were conducted for qualitative data.

Sampling Frame for Qualitative Data

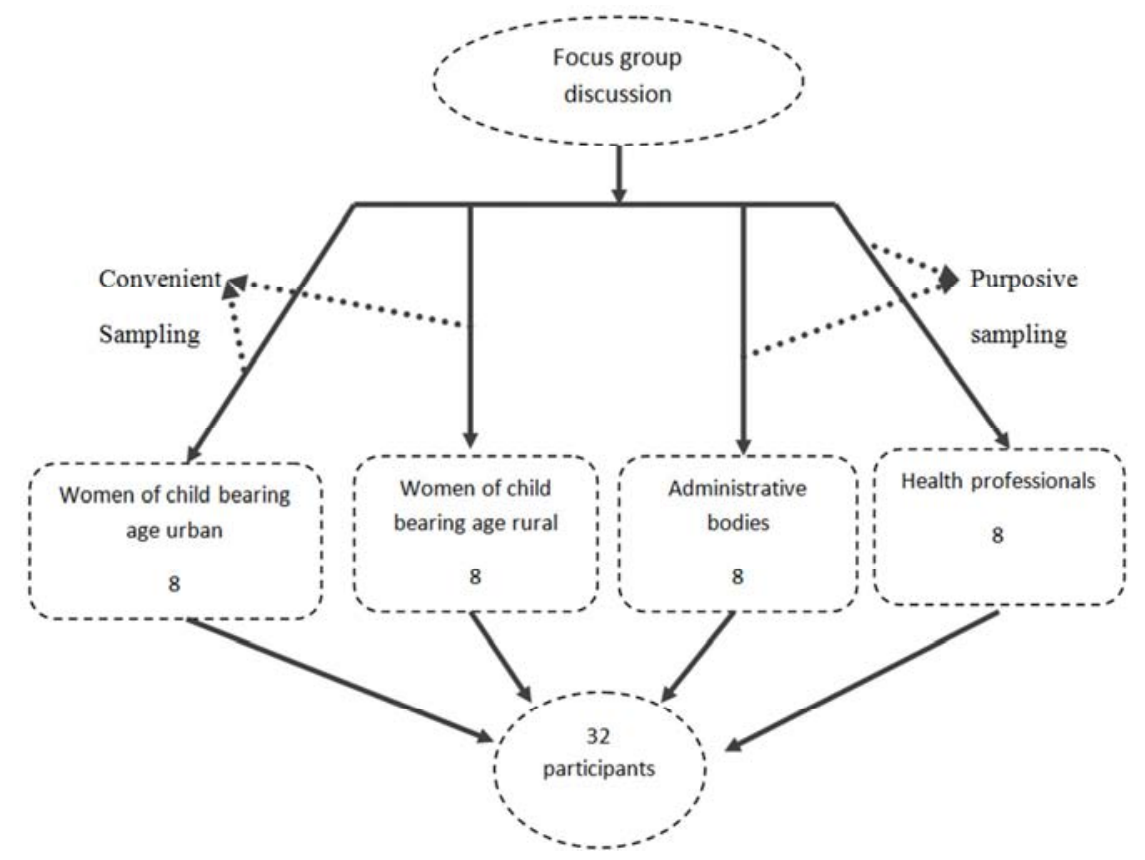

Figure 1. Schematic representation of sampling frame for qualitative data collection.

\subsubsection{Data Collection and Analysis}

Data were fed and analyzed using SPSS 16.0, descriptive analysis, bivariate and multivariate logistic regression was used to test significant associations of variables using Odds Ratio at $95 \%$ CI. The results of the analysis were discussed along with results of the quantitative study.

\section{Result}

Majority of the respondents $93.2 \%$ were housewives. The mean age for the respondents was 30.37 (S.d. \pm 7.565 ). About $78.9 \%$ of the respondents were rural and $21.1 \%$ were urban. The educational status of the respondents was $67.1 \%$ and $32.9 \%$ for illiterate and literate, respectively. (Table 1) 
Table 1. Socio-demographic Characteristics of Respondents in Egela (sub-woreda) Tigray Region, Northern of Ethiopia July-August 2011 ( $n=380$ ).

\begin{tabular}{|c|c|c|c|}
\hline \multicolumn{2}{|c|}{ Socio-demographic characteristics } & \multirow{2}{*}{$\begin{array}{l}\text { Frequency } \mathbf{N}=\mathbf{3 8 0} \\
19\end{array}$} & \multirow{2}{*}{$\begin{array}{l}\text { Percent (\%) } \\
5.0\end{array}$} \\
\hline \multirow{5}{*}{ Age during interview } & $15-19$ & & \\
\hline & $20-24$ & 86 & 22.6 \\
\hline & $25-29$ & 67 & 17.6 \\
\hline & $30-34$ & 78 & 20.5 \\
\hline & $>35$ & 130 & 34.2 \\
\hline \multirow{2}{*}{ Religion } & Orthodox & 378 & 99.5 \\
\hline & Muslim & 2 & 0.5 \\
\hline \multirow{2}{*}{ Ethnicity } & Tigrie & 376 & 98.9 \\
\hline & Amara & 4 & 1.1 \\
\hline \multirow{2}{*}{ Residency } & Rural & 300 & 78.9 \\
\hline & Urban & 80 & 21.1 \\
\hline \multirow{2}{*}{ Mother's educational status } & Literate & 124 & 32.1 \\
\hline & Illiterate & 256 & 67.9 \\
\hline \multirow{3}{*}{ Higher grade attended } & Read and write & 8 & 6.3 \\
\hline & $1-8$ & 105 & 83.3 \\
\hline & $9-12$ & 11 & 10.3 \\
\hline \multirow{2}{*}{ Husband Edu. Status } & Literate & 221 & 58.2 \\
\hline & Illiterate & 159 & 41.8 \\
\hline \multirow{5}{*}{ Husband edu. Level } & Read and write & 39 & 17.5 \\
\hline & $1-8$ & 158 & 70.9 \\
\hline & $9-12$ & 20 & 9.0 \\
\hline & $12+$ & 1 & 0.4 \\
\hline & Other & 5 & 2.2 \\
\hline \multirow{5}{*}{ Marital status } & Single & 2 & 5 \\
\hline & Married & 184 & 48.4 \\
\hline & Diseased husband & 18 & 4.7 \\
\hline & Separated & 166 & 47.7 \\
\hline & Divorced & 10 & 2.4 \\
\hline \multirow{3}{*}{ Mother occupation } & House wife & 354 & 93.2 \\
\hline & Merchant & 25 & 6.6 \\
\hline & Other & 1 & 0.3 \\
\hline \multirow{4}{*}{ Husband occupation } & Farmer & 310 & 81.6 \\
\hline & Merchant & 50 & 13.2 \\
\hline & Civil servant & 19 & 5.0 \\
\hline & Other & 1 & 0.3 \\
\hline \multirow{3}{*}{ Family size } & $1-2$ & 20 & 5.3 \\
\hline & $2-4$ & 116 & 30.5 \\
\hline & $>5$ & 244 & 64.2 \\
\hline \multirow{3}{*}{ Monthly income } & $<100$ & 46 & 12.1 \\
\hline & $100-499$ & 298 & 78.4 \\
\hline & $>500$ & 36 & 9.5 \\
\hline
\end{tabular}

The overall utilization of safe delivery service in subworeda Egela was $10.3 \%$. About $87.1 \%$ of the respondents had duration of labor $<12$ hour, and $12-24$ and $>24$ were the duration of labor for the other $9.5 \%$ and $2.6 \%$ of the respondents, respectively. Utilization of ANC in the study area according to WHO standard is $12.4 \%$, The greater part of the respondents $(40.5 \%)$ had travelled less than one hour to reach the health institution. The rest $34.5 \%$ and $25 \%$ travelled $1-2$ and $>2$ hours, respectively (Table 2). 
Table 2. Obstetric, Delivery Characteristics and Traditional Harmful Practices of the Respondents in Egela (sub-woreda), Tigray Region, Northern Ethiopia, July - August. 2011 ( $n=380)$.

\begin{tabular}{|c|c|c|c|}
\hline Variables & & Frequency $\mathbf{N}=\mathbf{3 8 0}$ & Percent (\%) \\
\hline \multirow{5}{*}{ Age during delivery } & $15-19$ & 68 & 17.9 \\
\hline & $20-24$ & 65 & 17.1 \\
\hline & $25-29$ & 80 & 21.1 \\
\hline & $30-34$ & 73 & 1932 \\
\hline & $>35$ & 94 & 24.7 \\
\hline \multirow{4}{*}{ Duration of labor } & $<12$ & 331 & 87.1 \\
\hline & $12-24$ & 36 & 9.5 \\
\hline & $>24$ & 10 & 2.6 \\
\hline & I don't remember & 3 & 0.8 \\
\hline \multirow{3}{*}{ Time spend to travel } & $<1$ & 154 & 40.5 \\
\hline & $1-2$ & 131 & 34.5 \\
\hline & $>2$ & 95 & 25 \\
\hline \multirow{2}{*}{ Place of delivery } & Home & 38 & 10.3 \\
\hline & Health institution & 342 & 89.7 \\
\hline \multirow{3}{*}{ Parity } & 1 & 66 & 17.4 \\
\hline & $2-4$ & 179 & 47.1 \\
\hline & $>=5$ & 135 & 35.5 \\
\hline \multirow{3}{*}{ Gravidity } & 1 & 58 & 15.3 \\
\hline & $2-4$ & 166 & 43.7 \\
\hline & $>=5$ & 156 & 41.1 \\
\hline \multirow{2}{*}{ ANC attendance } & Yes & 222 & 58.4 \\
\hline & No & 158 & 45.3 \\
\hline \multirow{4}{*}{$\mathrm{N}^{\mathrm{o}}$ of ANC visits } & One & 29 & 7.1 \\
\hline & Two & 59 & 15.5 \\
\hline & Three & 75 & 19.7 \\
\hline & Four and above & 47 & 12.4 \\
\hline \multirow{2}{*}{ TT vaccination } & Yes & 205 & 53.9 \\
\hline & No & 175 & 46.1 \\
\hline \multirow{2}{*}{ Complication of labor } & Yes & 39 & 10.3 \\
\hline & No & 341 & 89.7 \\
\hline \multicolumn{4}{|l|}{ Assistance during delivery } \\
\hline Health professional & & 1 & 0.3 \\
\hline TBAs & & 9 & 2.4 \\
\hline Relatives & & 205 & 53.9 \\
\hline Neighbor & & 122 & 32.1 \\
\hline No one & & 5 & 1.3 \\
\hline \multirow{2}{*}{ Abdominal messages } & Yes & 43 & 11.3 \\
\hline & No & 337 & 88.7 \\
\hline \multicolumn{4}{|l|}{ Reason for utilization } \\
\hline Health problem & & 19 & 47.5 \\
\hline Fear there might be pain & & 20 & 50 \\
\hline Other & & 1 & 2.5 \\
\hline
\end{tabular}

In bivariate analysis mothers whose ages were 35 years and above were less likely to utilize safe delivery service than women whose age was $15-19$ years $(\mathrm{OR}=0.09,95 \%$ $\mathrm{CI}=0.028,0.28)$. On the other hand, mothers that were at the age of 20-24 were slightly more to deliver at health institution than the women at $15-19$ years $(\mathrm{OR}=0.18,95 \%$ $\mathrm{CI}=0.58,0.60$ ).

About $6.3 \%$ of the rural and $25 \%$ of the urban participants delivered in health institution. The rural participants were less likely to deliver in health institution than the urban counter parts $(\mathrm{OR}=0.203,95 \% \mathrm{CI}=0.102,0.403)$.

Regarding the level of education of the literate participants, utilization of safe delivery tends to increase as the level of education increases. Therefore, participants with read and write and elementary level of education were less likely to deliver at health institution than participants that had secondary level of education $(\mathrm{OR}=0.82,95 \% \mathrm{CI}=0.007,0.92)$ and $(\mathrm{OR}=0.09,95 \% \mathrm{CI}=0.025,0.365)$, respectively. (Table 3$)$. 
Table 3. Association of Socio-demographic Factors of Respondents with Preference to Safe Delivery Services Utilization in Egela (Sub-woreda), Tigray, Northern Ethiopia June - August, 2011.

\begin{tabular}{|c|c|c|c|c|c|c|}
\hline \multirow{3}{*}{ Variables } & & \multicolumn{4}{|c|}{ Place of delivery } & \multirow{3}{*}{ Crud OR (95\% CI) } \\
\hline & & \multicolumn{2}{|l|}{ HI } & \multicolumn{2}{|c|}{ Home } & \\
\hline & & $\mathbf{N}$ & $\%$ & $\mathbf{N}$ & $\%$ & \\
\hline \multirow{5}{*}{ Age at interview } & $15-19$ & 10 & 14.7 & 58 & 85.3 & $1.00+$ \\
\hline & $20-24$ & 12 & 18.5 & 53 & 81.5 & $0.12(0.03,0.40)^{*}$ \\
\hline & $25-29$ & 4 & 5.0 & 76 & 95 & $0.18(0.58,0.60)^{*}$ \\
\hline & $30-34$ & 6 & 8.2 & 67 & 91.8 & $0.57(0.04,0.50)^{*}$ \\
\hline & $>35$ & 7 & 7.4 & 87 & 92.6 & $0.09(0.028,0.28)^{*}$ \\
\hline \multirow{2}{*}{ Religion } & Orthodox & 39 & 10.3 & 339 & 89.7 & $1.00+$ \\
\hline & Muslim & 0 & 0 & 2 & 100 & $0.0(0)$ \\
\hline \multirow{2}{*}{ Ethnicity } & Tigrie & 37 & 9.8 & 339 & 90.2 & $1.00+$ \\
\hline & Amara & 2 & 50 & 2 & 50 & $0.109(0.015-0.798 *$ \\
\hline \multirow{2}{*}{ Residency } & Rural & 19 & 6.3 & 281 & 93.7 & $0.203(0.102,0.403)^{*}$ \\
\hline & Urban & 20 & 25 & 60 & 75 & $1.00+$ \\
\hline \multirow{2}{*}{ Mother's Educational status } & Literate & 23 & 18.5 & 101 & 81.5 & $1.00+$ \\
\hline & illiterate & 16 & 6.2 & 240 & 93.8 & $3.416(1.73-6.73)^{*}$ \\
\hline \multirow{3}{*}{ Higher grade attended } & Read and write & 1 & 12.5 & 7 & 87.5 & $0.82(0 . .007,0.926)^{*}$ \\
\hline & $1-8$ & 15 & 14.3 & 90 & 83.7 & $0.095(0.025,0.365)^{*}$ \\
\hline & $9-12$ & 7 & 63.6 & 4 & 36.4 & $1.00+$ \\
\hline \multirow{5}{*}{ Marital status } & Single & 1 & 50.0 & 1 & 50 & $0.64(0.04,1.08)$ \\
\hline & Married & 11 & 6.0 & 173 & 94.0 & $1.00+$ \\
\hline & Diseased husband & 5 & 27.8 & 13 & 72.2 & $0.165(0.05,0.54)^{*}$ \\
\hline & Separated & 22 & 13.3 & 144 & 86.7 & $0.416(0.195,0.887)^{*}$ \\
\hline & Divorced & 0 & 1 & 10 & 100 & $1.027(0)$ \\
\hline \multirow{3}{*}{ Mother's occupation } & House wife & 30 & 8.5 & 324 & 91.5 & $1.00+$ \\
\hline & Merchant & 9 & 36.0 & 16 & 60.0 & $6.07(2.47,14.91)^{*}$ \\
\hline & Other & 0 & 0 & 1 & 100 & $0(0)$ \\
\hline \multirow{4}{*}{ Husband occupation } & Farmer & 20 & 6.5 & 290 & 93.5 & $0.19(0.06,0.59)^{*}$ \\
\hline & Merchant & 14 & 28.0 & 36 & 72 & $1.08(0.33,3.59)$ \\
\hline & Civil servant & 5 & 26.3 & 14 & 73.7 & $1.00+$ \\
\hline & Other & 0 & 0 & 1 & 100 & $0(0)$ \\
\hline \multirow{3}{*}{ Family size } & $1-2$ & 1 & 5.0 & 19 & 95.0 & $0.58(0.07,4.63)$ \\
\hline & $2-4$ & 18 & 15.5 & 98 & 84.5 & $2.05(1.04,4.05)^{*}$ \\
\hline & $>5$ & 20 & 8.2 & 224 & 91.8 & $1.00+$ \\
\hline \multirow{3}{*}{ Monthly income } & $<100$ & 6 & 13.0 & 40 & 87.0 & $0.34(0.11,1.03)$ \\
\hline & $100-499$ & 22 & 7.4 & 276 & 92.6 & $0.18(0.07,0.41)^{*}$ \\
\hline & $>500$ & 11 & 30.6 & 25 & 69.4 & $1.00+$ \\
\hline
\end{tabular}

$*=$ Significant results

$+=$ Reference category

About $14 \%$ of the respondents who attended ANC and $5.1 \%$ of the respondents who did not utilize ANC deliver in health institution. On the other hand $86 \%$ of the respondents who utilized ANC and $94.9 \%$ of the respondents who did not utilize ANC deliver at home. When we come to the tetanus vaccination of the respondents, women who had TT vaccination were seen to deliver at health institutions than those who had not. Thus, the respondents who had TT vaccination were more liable to utilize safe delivery service than the respondents who had not $(\mathrm{OR}=0.26,95 \% \mathrm{CI}=0.12,0.60)$. (Table 4). 
Table 4. Association of obstetric factors of respondents with preference to safe delivery services utilization in Egela (Sub-woreda), Tigray, Northern Ethiopia, June - August, 2011 (n=380).

\begin{tabular}{|c|c|c|c|c|c|c|}
\hline \multirow{3}{*}{ Variables } & & \multicolumn{4}{|c|}{ Place of delivery } & \multirow{3}{*}{ COR. 95\% CI } \\
\hline & & \multicolumn{2}{|c|}{ Health center } & \multicolumn{2}{|c|}{ Home } & \\
\hline & & $\mathbf{N}$ & $\%$ & $\mathbf{N}$ & $\%$ & \\
\hline \multirow{5}{*}{ Age during delivery } & $15-19$ & 10 & 14.7 & 58 & 85.3 & $1.00+$ \\
\hline & $20-24$ & 12 & 18.5 & 53 & 81.5 & $0.31(0.52,3.28)$ \\
\hline & $25-29$ & 4 & 5.0 & 76 & 95.0 & $0 . .30(0.09,1.02)$ \\
\hline & $30-34$ & 6 & 8.2 & 67 & 91.8 & $0.51(0.17,1.51)$ \\
\hline & $>35$ & 7 & 7.4 & 87 & 92.6 & $0.46(0.16,1.29)$ \\
\hline \multirow{3}{*}{ Gravidity } & 1 & 11 & 19.0 & 47 & 81 & $3.08(1.25,7.57)^{*}$ \\
\hline & $2-4$ & 17 & 10.2 & 149 & 89.8 & $1.50(0.68,3.32)$ \\
\hline & $>5$ & 11 & 7.1 & 145 & 92.9 & $1.00+$ \\
\hline \multirow{3}{*}{ Parity } & 1 & 12 & 18.2 & 54 & 81.8 & $3.11(1.23,7.81)^{*}$ \\
\hline & $2-4$ & 18 & 10.1 & 161 & 89.9 & $1.56(0.68,3.60)$ \\
\hline & $>5$ & 9 & 6.7 & 126 & 93.3 & $1.00+$ \\
\hline \multirow{3}{*}{ Distance of health institution } & $0-1$ & 28 & 18.2 & 126 & 81.8 & $1.00+$ \\
\hline & $2-4$ & 5 & 3.8 & 126 & 96.2 & $0.17(0.06,0.47)^{*}$ \\
\hline & $>5$ & 6 & 6.3 & 89 & 93.7 & $0.30(1.31,8.29)^{*}$ \\
\hline \multirow{3}{*}{ Husband outlook } & Positive & 37 & 10.5 & 315 & 89.5 & $0.64(0.13,3.02)$ \\
\hline & Negative & 2 & 15.4 & 11 & 84.6 & $1.00+$ \\
\hline & I don't know & 0 & 0 & 15 & 100 & 0 \\
\hline \multirow{2}{*}{ Complications } & Yes & 5 & 11.6 & 38 & 88.4 & $1.17(0.43,3.18)$ \\
\hline & No & 24 & 10.1 & 303 & 89.9 & $1.00+$ \\
\hline \multirow{2}{*}{ ANC attendance } & Yes & 31 & 14.0 & 191 & 86 & $3.04(1.35,6.81)^{*}$ \\
\hline & No & 8 & 5.1 & 150 & 94.9 & $1.00+$ \\
\hline \multirow{2}{*}{ TT vaccination } & Yes & 31 & 15.1 & 174 & 84.9 & $0.26(0.12,0.60)^{*}$ \\
\hline & No & 8 & 4.6 & 167 & 95.4 & $1.00+$ \\
\hline \multirow{3}{*}{ Complication history } & Yes & 2 & 6.2 & 30 & 93.8 & $1.00+$ \\
\hline & No & 25 & 9.0 & 253 & 91.0 & $1.53(0.34,6.78)$ \\
\hline & Beginner & 12 & 17.4 & 57 & 82.6 & $3.26(0.68,15.52)$ \\
\hline \multirow{2}{*}{ Fear of problems } & Yes & 30 & 11.3 & 236 & 88.7 & $0.67(0.30,1.47)$ \\
\hline & No & 9 & 7.9 & 105 & 92.1 & $1.00+$ \\
\hline
\end{tabular}

*= Significant values

$+=$ Reference category

The net effect of each variable on the status of use of safe delivery was measured by entering variables that have a statistically significant association in the bivarite regression analysis to multivariate regression analysis model. However, only two of the variables were statistically significant. The results of the multivariate analysis show that monthly income and women's level of education were the independent predictors of utilization of safe delivery service utilization. (Table 5)

Table 5. Adjusted for socio-demographic and obstetric factors determining preference of place of delivery of respondents in Egela (Sub-woreda), Tigray, Northern Ethiopia, June-August, $2011(n=380)$.

\begin{tabular}{|c|c|c|c|c|c|c|c|}
\hline \multirow{3}{*}{ Variables } & & \multicolumn{4}{|c|}{ Place of Delivery } & \multirow{3}{*}{ COR $(95 \%$ CI $)$} & \multirow{3}{*}{ AOR (95CI) } \\
\hline & & \multicolumn{2}{|l|}{ HI } & \multicolumn{2}{|c|}{ Home } & & \\
\hline & & $\mathbf{N}$ & $\%$ & $\mathbf{N}$ & $\%$ & & \\
\hline \multirow{5}{*}{ Age at interview } & $15-19$ & 10 & 14.7 & 58 & 85.3 & 1.00 & 1.00 \\
\hline & $20-24$ & 12 & 18.5 & 53 & 81.5 & $0.12(0.03,0.40)^{*}$ & $0.43(0.08,2.07)$ \\
\hline & $25-29$ & 4 & 5.0 & 76 & 95 & $0.18(0.58,0.60)^{*}$ & $0.58(0.08,4.30)$ \\
\hline & $30-34$ & 6 & 8.2 & 67 & 91.8 & $0.57(0.04,0.50)^{*}$ & $1.68(0.17,14.46)$ \\
\hline & $>35$ & 7 & 7.4 & 87 & 92.6 & $0.09(0.02,0.28)^{*}$ & $0.34(0.02,4.22)$ \\
\hline
\end{tabular}




\begin{tabular}{|c|c|c|c|c|c|c|c|}
\hline \multirow{3}{*}{ Variables } & & \multicolumn{4}{|c|}{ Place of Delivery } & \multirow{3}{*}{$\operatorname{COR}(95 \% \mathrm{CI})$} & \multirow{3}{*}{ AOR (95CI) } \\
\hline & & \multicolumn{2}{|l|}{ HI } & \multicolumn{2}{|c|}{ Home } & & \\
\hline & & $\mathbf{N}$ & $\%$ & $\mathbf{N}$ & $\%$ & & \\
\hline \multirow{2}{*}{ Ethnicity } & Tigrie & 37 & 9.8 & 339 & 90.2 & 1.00 & 1.00 \\
\hline & Amara & 2 & 50 & 2 & 50 & $0.10(0.01-0.79 *$ & $2.38(0.16,33.73)$ \\
\hline \multirow{2}{*}{ Residency } & Rural & 19 & 6.3 & 281 & 93.7 & $0.203(0.102,0.403)^{*}$ & $1.06(0.15,7.25)$ \\
\hline & Urban & 20 & 25 & 60 & 75 & 100 & 1.00 \\
\hline \multirow{2}{*}{ Mom. Edu. Status } & Literate & 23 & 18.5 & 101 & 81.5 & 1.00 & 1.00 \\
\hline & illiterate & 16 & 6.2 & 240 & 93.8 & $3.416(1.73-6.73)^{*}$ & 0 \\
\hline \multirow{3}{*}{ Higher Gr. Attended } & Read and write & 1 & 12.5 & 7 & 87.5 & $0.82(0 . .007,0.926)^{*}$ & $0.08(0.008,1.02)$ \\
\hline & $1-8$ & 15 & 14.3 & 90 & 83.7 & $0.095(0.025,0.365)^{*}$ & $0.06(0.01,0.27)^{*}$ \\
\hline & $9-12$ & 7 & 63.6 & 4 & 36.4 & 1.00 & 1.00 \\
\hline \multirow{3}{*}{ Distance of HI } & $0-1$ & 28 & 18.2 & 126 & 81.8 & 1.00 & 1.00 \\
\hline & $1-2$ & 5 & 3.8 & 126 & 96.2 & $0.17(0.06,0.47)^{*}$ & $0.53(0.11,2.47)$ \\
\hline & $>2$ & 6 & 6.3 & 89 & 93.7 & $0.30(1.31,8.29)^{*}$ & $0.37(0.03,3.60)$ \\
\hline \multirow{2}{*}{ ANC attendance } & Yes & 31 & 14.0 & 191 & 86 & $3.04(1.35,6.81)^{*}$ & $1.00(1.12,8.32)$ \\
\hline & No & 8 & 5.1 & 150 & 94.9 & 1.00 & 1.00 \\
\hline \multirow{2}{*}{ TT vaccination } & Yes & 31 & 15.1 & 174 & 84.9 & $0.26(0.12,0.60)^{*}$ & $2.33(0.56,9.55)$ \\
\hline & No & 8 & 4.6 & 167 & 95.4 & 1.00 & 1.00 \\
\hline \multirow{5}{*}{ Marital status } & Single & 1 & 50.0 & 1 & 50 & $0.64(0.04,1.08)$ & 0 \\
\hline & Married & 11 & 6.0 & 173 & 94.0 & 1.00 & 1.00 \\
\hline & Diseased husband & 5 & 27.8 & 13 & 72.2 & $0.165(0.05,0.54)^{*}$ & $2.27(0.24,21.53)$ \\
\hline & Separated & 22 & 13.3 & 144 & 86.7 & $0.416(0.195,0.887)^{*}$ & $0.83(0.21,3.19)$ \\
\hline & Divorced & 0 & 0 & 10 & 100 & $1.027(0)$ & 0 \\
\hline \multirow{3}{*}{ Mother's occu } & House wife & 30 & 8.5 & 324 & 91.5 & 1.00 & 1.00 \\
\hline & Merchant & 9 & 36.0 & 16 & 60.0 & $6.07(2.47,14.91)^{*}$ & $0.52(0.43,6.37)$ \\
\hline & Other & 0 & 0 & 1 & 100 & $0(0)$ & 0 \\
\hline \multirow{4}{*}{ Husband occu } & Farmer & 20 & 6.5 & 290 & 93.5 & $0.19(0.06,0.59)^{*}$ & $1.03(0.09,11.64)$ \\
\hline & Merchant & 14 & 28.0 & 36 & 72 & $1.08(0.33,3.59)$ & $1.08(0.09,5.37)$ \\
\hline & Civil servant & 5 & 26.3 & 14 & 73.7 & 1.00 & 1.00 \\
\hline & Other & 0 & 0 & 1 & 100 & $0(0)$ & 0 \\
\hline \multirow{3}{*}{ Family size } & $1-2$ & 1 & 5.0 & 19 & 95.0 & $0.58(0.07,4.63)$ & 0 \\
\hline & $2-4$ & 18 & 15.5 & 98 & 84.5 & $2.05(1.04,4.05)^{*}$ & $2.57(0.83,7.92)$ \\
\hline & $>5$ & 20 & 8.2 & 224 & 91.8 & 1.00 & 1.00 \\
\hline \multirow{3}{*}{ Monthly income } & $<100$ & 6 & 13.0 & 40 & 87.0 & $0.34(0.11,1.03)$ & $0.13(0.01,1.23)$ \\
\hline & $100-499$ & 22 & 7.4 & 276 & 92.6 & $0.18(0.07,0.41)^{*}$ & $0.22(0.05,0.82)^{*}$ \\
\hline & $>500$ & 11 & 30.6 & 25 & 69.4 & 1.00 & 1.00 \\
\hline
\end{tabular}

Note. Mom. Edu. $=$ Mothers educational status

Husband/mother Occu. $=$ Husband or maternal educational status

$\mathrm{HI}=$ health institution

$*=$ Significant values

$+=$ Reference category

\section{Discussion}

The utilization of institutional delivery service in the subworeda was $25 \%$ for urban and $6.3 \%$ for rural. And the overall magnitude of utilization of safe delivery in Egela is about $10.3 \%$. The remained $89.7 \%$ of the women give birth at home. This finding is higher than the Ethiopian demographic and health survey (EDHS, 2005) in which the utilization for nationally and for Tigray region were $6 \%$ and $6.1 \%$ [10], respectively. The reason for better utilization could be due to the efforts exerted to increase utilization of safe delivery within the last five years. In addition, this could be due to the organized tasks done in the sub-woreda to improve utilization of institutional delivery as indicated by the FGD participants. This finding is a little bit lower than the result for delivery service utilization indicted by health 
and health related indicators $2006 / 2007$ prepared by ministry of health [11]. However, it is consistent with the other studies done in $2010 \& 2008$ [5, 12]. Possibly the reason for this could be the annual report prepared by the Ministry of Health $(\mathrm{MOH})$ is institution based report. On the contrary, our study was community based, thus looking this much difference is likely.

Women's age during interview was found to be important indicator of utilization of safe delivery services. The utilization of safe delivery service increases as we go down from higher age to lower age. The participants whose age was $>35$ were less likely to deliver at health institution than the participants whose age was $15-19(\mathrm{OR}=0.09,95 \% \mathrm{CI}$ : $0.028,0.28)$. Women who were at higher age had the experience to deliver at home and may reduce their tendency to deliver at health institution. This result is consistent with other studies done on maternal health care seeking behaviors $[10,13]$.

The results of the current study revealed that utilization of safe delivery service is significantly influenced by residency. Women who reside in rural areas were 0.2 times less likely to deliver at health institution than those who reside in urban $(\mathrm{OR}=0.20,95 \% \mathrm{CI}: 0.102,0.403)$. This study is in line with finding in North Gonder zone although a little bit lower, where the rural women were 0.03 times less likely to deliver at health institution than the urban [14] and others [5, 15]. The reason may be the urban women are nearest to media, health institution and relatively economically better than the rural counterparts [16]. The result of this study showed to better result in institutional delivery than the study done in north Gonder zone. This may be due to the time gab the studies done and the efforts being undertaken by the government to meet the MDGs 5.

Educational status had shown to be independent predictor of place of delivery while the effects of other variables were controlled in the multivariate logistic regression model. Those participants whose educational levels were elementary school were less likely to deliver at health institution than secondary school level $(\mathrm{AOR}=0.06,95 \%$ CI: 0.01, 0.27).

Maternal occupation was seen to affect institutional delivery service utilization. Merchant women were six times more likely to deliver at health institution than women who were housewives $(\mathrm{OR}=6.07,95 \% \mathrm{CI}: 2.47,14.91)$. This is consistent with other study done in Metekel Zone [12].

Husband occupation was significantly associated with utilization of institutional delivery service. Women who had partner farmers were less likely to deliver in health institution than those women whose husband was civil servants $(\mathrm{OR}=0.19,95 \% \mathrm{CI}: 0.06,0.59)$. This study were supported by the another study, where women who had partner skilled worker had about 1.8 times higher odds of with professional assistance than women who were not skilled professional (5).

Family size had showed significant association with place of delivery. the women who had 2-4 family were about two times more likely to deliver at health institution than those who have $>5$ family size $(\mathrm{OR}=2.05,95 \% \mathrm{CI}$ : $1.04,4.05)$.
This study was in line with other studies done in developing countries $[15,17]$.

Monthly income of the women also showed statistically significant association with place of delivery. Thus, the women whose monthly income was 100-499 were about three times less likely to deliver at health institution than those women whose monthly income was $\geq 500$ (OR=0.18, 95\% CI: $0.07,0.41)$. This variable was to be the independent predictor of place of delivery. The respondents whose monthly income was 100-499 were less likely to deliver at health institution than those participants whose income $>500$ birr $(\mathrm{AOR}=0.22,95 \% \mathrm{CI}$ : 0.05, 0.82) (10).

Distance of the health institution was also another determinant factor for utilization of safe delivery services. The women who reside 1-2 and $>2$ hours far from the health institution on foot were less likely to deliver in health institution than those who reside less than 1 hour far from the HI on foot $(\mathrm{OR}=0.17,95 \% \mathrm{CI}: 0.06,0.47)$ and $(\mathrm{OR}=0.30$, $95 \%$ CI: $1.31,8.29)$. This finding was supported by other findings $[15,18,19]$.

Antenatal care (ANC) visit positively predicts use of safe delivery services and it is more effective in preventing adverse pregnancy outcome if continued throughout the pregnancy $[5,14,15]$. The more the exposure the women have for the health institution, the more the probability of utilizing. The FGD participants explained that there were health education programs during $\mathrm{ANC}$ attendance time; this might also contribute for better utilization of the institutional delivery than those who did not attend. Similarly, TT vaccination and institutional delivery was seen being significantly associated in our study. The participants who had TT vaccination were more likely to utilize safe delivery service than those who did not. The above explained reason for ANC may as well describe for TT vaccination too.

\section{Conclusion and Recommendation}

In conclusion, this study demonstrated that utilization of safe delivery service is inadequate in the area as clearly depicted in the results during the period of five years preceding the survey. The most important factors influencing utilization of safe delivery service were demographic and socio-cultural in characteristics..

The main reasons given by the FGD participants for not attending ANC were fear of injections, distant health facility and work overload. Other barriers found to be important of safe delivery service were distance of health institution from home, absence of road and ambulance services as clearly stated by the FDG participants.

As women's education is an important factor for the institutional delivery, improving education among girls, beyond the primary school, needs to be strongly encouraged and aware of the women the institutional delivery is cost free.

Since pregnancy related complications are the main reasons for utilization of health facilities, community awareness program must focus on the danger signs during 
pregnancy and childbirth.

\section{References}

[1] Abouzahar C, Wardlaw T. Maternal mortality in 2000: Estimates developed by WHO, UNICEF, UNFPA. Geneva; WHO; 2004.

[2] UNICEF. The state of the world's children 2007. Maternal and Newborn Health. New York, 2007.

[3] Moccia P. Progress for children. A report card on maternal mortality. UNICEF 2009; (7): 1-2.

[4] Mekonnen Y. Patterns of maternity care service utilization in Southern Ethiopia: Evidence from a community and family survey. Ethiop. J. Health Dev. 2003; 17 (1): 27-33.

[5] Dagne E. Role of socio-demographic factors on utilization of maternal health care services in Ethiopia. 2010.

[6] Tigray Regional Health Bureau (TRHB). Health management information system. Tigray health Bureau 2004 profile. Tigray health Bureau, Mekelle, 2005.

[7] Amira Y N. Making skilled attendance at child in Tigray region, Ethiopia possible.

[8] United Nations (UN). The Millennium Development Goals Report. New York, 2008.

[9] Mekonnen, Y, Mekonnen A. Utilization of Maternal Health Care Services in Ethiopia. 2002; Calverton, Maryland, USA: ORC Macro.

[10] Central Statistical Agency [Ethiopia] and ORC Macro. Ethiopia Demographic and Health Survey 2005. Addis Ababa, Ethiopia and Calverton, Maryland, USA: Central Statistical Agency and ORC Macro.
[11] Federal Democratic Republic of Ethiopia Ministry of Health. Health and health related indicator. 2006/2007.

[12] Tura G, G/Mariam A. Safe Delivery Service Utilization in Metekel Zone, North West Ethiopia. Ethiopian J Health Sci. March 2008; 17 (4): 213-221.

[13] Ethiopian Society of Population Studies. Maternal Health Care Seeking Behavior in Ethiopia: In-depth Analysis of the Ethiopian Demographic and Health Survey 2005, Addis Ababa Oct, 2008, 14-15.

[14] Nigussie M, Mitike G. Assessment of safe delivery service utilization among women of childbearing age in north Gondar Zone, North West Ethiopia. Ethiop J Health Dev. 200; 18 (3): 145-152.

[15] Addai I. Demographic and socio-cultural factors influencing use of maternal health services in Ghana. Afr J Reprod Health. 1998; Apr 2 (1): 73-80.

[16] Sari K. Socio-Economic and Demographic Determinants of Maternal Health Care Utilization in Indonesia. Faculty of Social Sciences, the Flinders University of South Australia, 2009.

[17] T. T. Awoyemi, O. A. Obayelu and H. I. Opaluwa. Effect of Distance on Utilization of Health Care Services in Rural Kogi State, Nigeria. J Hum Ecol, 2011; 35 (1): 1-9.

[18] Abbas AA, Walker GJ. Determinants of the utilization of maternal and child health services in Jordan. Int J Epidemiol. 1986 Sep; 15 (3): 404-7.

[19] Sauerborn R, Nougtara A, Diesfeld HJ. Low utilization of community health workers: results from a household interview survey in Burkina Faso. Soc Sci Med. 1989; 29 (10): 1163-74. 